\title{
Assessment of the Content of Phenolics and Antioxidant Action of Inflorescences and Leaves of Selected Species from the Genus Sorbus Sensu Stricto
}

\author{
Monika A. Olszewska ${ }^{1, *}$, Slawomira Nowak ${ }^{1}$, Piotr Michel ${ }^{1}, \operatorname{Piotr}_{\text {Banaszczak }^{2}}$ and \\ Agnieszka Kicel ${ }^{1}$
}

1 Department of Pharmacognosy, Faculty of Pharmacy, Medical University of Lodz, 1 Muszynski St., 90-151 Lodz, Poland; E-Mails: slawomira.nowak@umed.lodz.pl (S.N.); piotr.michel@umed.lodz.pl (P.M.); agnieszka.kicel@umed.lodz.pl (A.K.)

2 Arboretum, Rogow Forestry Experimental Station, Warsaw University of Life Sciences (SGGW), 95-063 Rogow, Poland; E-Mail: arbor@wp.pl (P.B.)

* Author to whom correspondence should be addressed; E-Mail: monika.olszewska@umed.lodz.pl; Tel.: +48 42677 9169; Fax: +48 426788398.

Received: 5 November 2010; in revised form: 26 November 2010 / Accepted: 30 November 2010 / Published: 2 December 2010

\begin{abstract}
In order to find new sources of natural antioxidants, the antioxidant potential of $70 \%$ methanolic extracts from the inflorescences and leaves of 16 species from the genus Sorbus s.s. was evaluated using two complementary in vitro test systems: the DPPH (2,2-diphenyl-1-picrylhydrazyl) radical-scavenging assay and the AAPH [2,2'-azobis-(2amidinopropane)dihydrochloride]-induced linoleic acid (LA) peroxidation test. The radical-scavenging capacities of the extracts towards the DPPH radical were in the range of 0.25-0.86 millimolar Trolox ${ }^{\circledR}$ equivalents/g dry weight. They were significantly correlated $(r=-0.8089, p<0.001)$ with the results of the LA-peroxidation test, indicating the Sorbus extracts to be universal antioxidants. Significant linear correlations were also found between the different antioxidant potentials and total phenolic contents as estimated by the Folin-Ciocalteu method and further verified by serial determinations of proanthocyanidins, chlorogenic acid isomers and flavonoids $(|r|$ in the range of $0.71-0.95, p<0.001)$. Cluster analysis of the data matrix identified the ten samples (inflorescences of $S$. aucuparia, $S$. pohuashanensis, S. decora, S. koehneana, S. commixta, S. gracilis, and S. sitchensis, and the leaves of $S$. wilfordii, S. pogonopetala, and $S$. gracilis) exhibiting the highest
\end{abstract}


antioxidant activity and total phenolic levels and therefore the greatest potential as effective sources for natural health products.

Keywords: Sorbus; antioxidant activity; phenolic content

\section{Introduction}

The large genus Sorbus sensu stricto (Rosaceae, Maloideae) is confined to the Northern Hemisphere and has a circumboreal distribution, being commonly found in Europe, North Africa, Asia and northern North America [1]. The majority of the over 70 species included in the genus have not been phytochemically characterised, except for a few species with known ethnomedical significance such as S. aucuparia L., S. americana Marsh., S. cashmiriana Hedl., S. commixta Hedl., and S. decora (Sarg.) C.K. Schneid. These plants are reported to have antioxidative [2-5], anti-atherogenic [6], antiinflammatory [7], anti-diabetic [4], vasoprotective and vasorelaxant activities [8]. Most of these bioactivities can be explained by the presence of phenolic constituents. Indeed, a direct correlation between high antioxidant capacity and total phenolic content has been found for numerous species representing the Sorbus genera sensu stricto (s.s.) [2,3] and sensu lato (s.1.) [9,10]. The known Sorbus phenolics range from simple phenolic acids, their esters with quinic acid (mostly caffeoylquinic acids), flavonols (conjugates of quercetin, kaempferol, and sexangularetin), anthocyanins (cyanidin and pelargonidin derivatives), and tannin-type proanthocyanidins $[2,3,10]$.

Phenolic compounds are recognised as beneficial to human health and disease prevention, mostly due to their antioxidant activity and ability to neutralize reactive oxygen species (ROS). Under oxidative stress conditions, ROS can react with important biomolecules, causing cellular injury and the development of chronic diseases, such as atherosclerosis, coronary diseases, cancer, and neurodegenerative brain disorders. To ensure the optimum protection from the over-production of ROS, there is a need to provide antioxidants as part of the diet [11]. Antioxidants are also required to preserve food for prolonged storage and transport [11]. Food and pharmaceutical products are thus normally supplemented with synthetic phenolic antioxidants such as butylated hydroxyanisole (BHA) or butylated hydroxytoluene (BHT). However, natural plant phenolics may be more effective at reducing ROS levels compared to single synthetic compounds due to the synergistic actions of a wide range of active molecules existing in plant products [11]. In addition, the dietary intake of synthetic antioxidants could cause genotoxicity and carcinogenicity at high concentrations [11]. On the other hand, many phenolic constituents of herbal medicines and dietary plants have been identified as safe and potent antioxidants, functioning as free radical scavengers, reducing agents and chelators of transition metal ions [12]. The search for rich sources of natural antioxidants has, therefore, received much attention, and efforts have been made to identify plant extracts or compounds capable of replacing synthetic ones $[13,14]$.

Although a variety of plant materials (herbs, leaves, flowers, fruits, vegetables, etc.) have been studied for antioxidant activity and phenolic content, only a few have been found to be sufficiently rich in phenolics to be used for the cost-effective production of natural antioxidants [13,14]. An ideal antioxidant plant material would fulfil several criteria. These include mainly potent antioxidant action 
in various test systems (universal chemistry), a high level of total phenolics (not less than $8-10 \%$ dry weight ( $\mathrm{dw}$ ) of gallic acid equivalents, GAE), and low toxicity.

The results of previous studies of the genus Sorbus s.l. revealed that several species are promising sources of powerful antioxidants $[2-5,9,10]$. Significantly high total phenolic contents have been found in the inflorescences $(11.83 \% \mathrm{dw}$ GAE) and leaves $(9.09 \% \mathrm{dw}$ GAE) of $S$. aucuparia, and were correlated with the universal, potent antioxidant capacities of the appropriate extracts as measured by three different in vitro test systems [3]. It is noteworthy that the levels of phenolics and antioxidant activities found for S. aucuparia (the model species for the genus Sorbus s.s.) were higher than those observed for S. aria, S. intermedia and S. torminalis (species representing subgenera Aria and Torminaria from the genus Sorbus s.1.) [3,10]. However, there have been no prior reports on the antioxidant activity and phenolic levels of inflorescences and leaves of any species from the genus Sorbus s.s. with the exception of S. aucuparia.

Thus, the aim of this project was to screen the inflorescences and leaves of 16 selected species from the genus Sorbus s.s. (Table 1), including S. aucuparia, with respect to their phenolic profile and antioxidant activity. The plant extracts were assayed using two complementary in vitro test systems: the DPPH free radical-scavenging method and the AAPH-induced linoleic acid peroxidation test. To identify the compounds responsible for the tested activity, the quantitative phenolic profiles of the plant materials were monitored by HPLC and by UV-photometric methods, and the relationship between the antioxidant capacity and the phenolic content was investigated. Finally, all data were subjected to hierarchical cluster analysis to distinguish the group of species and plant materials with the greatest potential as valuable sources of natural antioxidants and candidates for in vivo studies of antioxidant protection.

Table 1. Antioxidant activity of the studied Sorbus species as measured by the DPPH free radical-scavenging assay and LA-peroxidation test.

\begin{tabular}{|c|c|c|c|c|c|}
\hline \multirow{3}{*}{ Sample No. } & \multicolumn{2}{|l|}{ Plant sources } & \multicolumn{3}{|c|}{ Antioxidant activity ${ }^{b}$} \\
\hline & \multirow[b]{2}{*}{ Scientific name } & \multirow{2}{*}{$\begin{array}{l}\text { Plant part } \\
\text { tested }^{\mathrm{a}}\end{array}$} & \multicolumn{2}{|c|}{ DPPH EC $\mathrm{E}_{50}$} & \multirow[b]{2}{*}{$\begin{array}{l}\text { LA peroxidation } \\
(\% \text { inhibition })\end{array}$} \\
\hline & & & $(\mu \mathrm{g} / \mathrm{mL})^{\mathrm{c}}$ & $\underset{(\mathrm{mmol} / \mathrm{g})}{\operatorname{TEA}}$ & \\
\hline 1. & Sorbus aucuparia L. & I & $16.69 \pm 0.26^{\mathrm{A}, \mathrm{B}}$ & 0.78 & $68.34 \pm 0.59^{\mathrm{A}}$ \\
\hline 2. & Sorbus aucuparia L. & $\mathrm{L}$ & $24.10 \pm 0.29^{\mathrm{C}}$ & 0.54 & $58.69 \pm 0.46^{\mathrm{B}, \mathrm{C}}$ \\
\hline 3. & $\begin{array}{l}\text { Sorbus pohuashanensis (Hance) } \\
\text { Hedl. }\end{array}$ & I & $17.89 \pm 0.55^{\mathrm{B}, \mathrm{D}}$ & 0.73 & $68.69 \pm 1.24^{\mathrm{A}}$ \\
\hline 4. & $\begin{array}{l}\text { Sorbus pohuashanensis (Hance) } \\
\text { Hedl. }\end{array}$ & $\mathrm{L}$ & $43.86 \pm 1.51^{\mathrm{E}}$ & 0.30 & $50.21 \pm 0.96^{\mathrm{D}}$ \\
\hline 5. & Sorbus scalaris Koehne & I & $27.65 \pm 1.09^{\mathrm{F}}$ & 0.47 & $55.23 \pm 1.46^{\mathrm{E}}$ \\
\hline 6. & Sorbus scalaris Koehne & $\mathrm{L}$ & $57.86 \pm 1.63^{\mathrm{G}}$ & 0.23 & $41.70 \pm 1.05^{\mathrm{F}}$ \\
\hline 7. & Sorbus prattii Koehne var. prattii & $\mathrm{L}$ & $24.26 \pm 0.45^{\mathrm{C}}$ & 0.54 & $57.51 \pm 0.87^{\mathrm{B}}$ \\
\hline 8. & Sorbus americana Marsh. & $\mathrm{L}$ & $38.76 \pm 0.84^{\mathrm{H}}$ & 0.34 & $54.29 \pm 0.85^{\mathrm{E}}$ \\
\hline 9. & Sorbus commixta Hedl. & I & $23.22 \pm 0.33^{\mathrm{C}}$ & 0.56 & $78.21 \pm 1.61^{\mathrm{G}}$ \\
\hline 10. & Sorbus commixta Hedl. & $\mathrm{L}$ & $28.56 \pm 0.64^{\mathrm{F}}$ & 0.46 & $58.65 \pm 1.28^{\mathrm{B}, \mathrm{C}}$ \\
\hline 11. & $\begin{array}{l}\text { Sorbus decora (Sarg.) C.K. } \\
\text { Schneid. }\end{array}$ & I & $16.20 \pm 0.27^{\mathrm{A}}$ & 0.81 & $70.99 \pm 1.39^{\mathrm{H}}$ \\
\hline 12. & $\begin{array}{l}\text { Sorbus decora (Sarg.) C.K. } \\
\text { Schneid. }\end{array}$ & $\mathrm{L}$ & $27.21 \pm 0.72^{\mathrm{F}}$ & 0.48 & $59.99 \pm 0.97^{\mathrm{C}}$ \\
\hline 13. & Sorbus wilfordii Koehne & $\mathrm{L}$ & $15.23 \pm 0.54^{\mathrm{A}}$ & 0.86 & $86.92 \pm 1.15^{\mathrm{I}}$ \\
\hline 14. & $\begin{array}{l}\text { Sorbus sambucifolia (Cham. \& } \\
\text { Schltdl.) M. Roem. }\end{array}$ & $\mathrm{I}$ & $28.03 \pm 0.80^{\mathrm{F}}$ & 0.47 & $58.12 \pm 1.50^{\mathrm{B}, \mathrm{C}}$ \\
\hline
\end{tabular}


Table 1. Cont.

\begin{tabular}{lllccc}
\hline 15. & $\begin{array}{l}\text { Sorbus sambucifolia (Cham. \& } \\
\text { Schltdl.) M. Roem. }\end{array}$ & $\mathrm{L}$ & $52.63 \pm 1.25^{\mathrm{I}}$ & 0.25 & $54.03 \pm 1.05^{\mathrm{E}}$ \\
16. & $\begin{array}{l}\text { Sorbus gracilis (Sieb. \& Zucc.) K. } \\
\text { Koch }\end{array}$ & $\mathrm{I}$ & $19.09 \pm 0.69^{\mathrm{D}, \mathrm{J}}$ & 0.68 & $73.01 \pm 1.09^{\mathrm{J}}$ \\
& & & & \\
17. & Sorbus gracilis (Sieb. \& Zucc.) K. & $\mathrm{L}$ & $20.71 \pm 0.66^{\mathrm{J}}$ & 0.63 & $70.72 \pm 1.00^{\mathrm{H}}$ \\
& Koch & $\mathrm{I}$ & $20.75 \pm 0.40^{\mathrm{J}}$ & 0.63 & $68.26 \pm 0.78^{\mathrm{A}}$ \\
18. & Sorbus sitchensis M. Roem. & $\mathrm{L}$ & $54.23 \pm 1.08^{\mathrm{K}}$ & 0.24 & $53.13 \pm 0.86^{\mathrm{E}}$ \\
19. & Sorbus sitchensis M. Roem. & $\mathrm{L}$ & $48.59 \pm 1.05^{\mathrm{L}}$ & 0.27 & $53.59 \pm 0.78^{\mathrm{E}}$ \\
20. & Sorbus cashmiriana Hedl. & $\mathrm{I}$ & $16.20 \pm 0.52^{\mathrm{A}}$ & 0.81 & $73.34 \pm 1.07^{\mathrm{J}}$ \\
21. & Sorbus koehneana C.K. Schneid. & $\mathrm{L}$ & $24.74 \pm 0.34^{\mathrm{C}}$ & 0.53 & $54.15 \pm 0.94^{\mathrm{E}}$ \\
22. & Sorbus koehneana C.K. Schneid. & $\mathrm{L}$ & $19.87 \pm 0.48^{\mathrm{J}}$ & 0.66 & $74.73 \pm 1.13^{\mathrm{J}}$ \\
23. & Sorbus pogonopetala Koehne & $\mathrm{L}$ & $23.30 \pm 0.56^{\mathrm{C}}$ & 0.56 & $63.77 \pm 0.70^{\mathrm{K}}$ \\
24. & Sorbus setschwanensis (C.K. & & & & \\
& Schneid.) Koehne & & $1.44 \pm 0.05$ & & $88.38 \pm 1.15$ \\
Quercetin & Srolox & & $3.27 \pm 0.10$ & & $92.74 \pm 1.10$ \\
\hline
\end{tabular}

${ }^{\mathrm{a}} \mathrm{I}$, inflorescences; L, leaves. ${ }^{\mathrm{b}}$ Results are mean values of triplicate analyses \pm S.D. Different superscripts (capitals) in each column indicate significant differences in the mean values at $p<0.05$. ${ }^{\mathrm{c}, \mathrm{d}}$ Scavenging efficiency (amount of antioxidant needed to decrease the initial DPPH concentration by $50 \%$ ) expressed as follows: ${ }^{c}$ in $\mu \mathrm{g}$ of dry plant material or the standard $/ \mathrm{mL}$ of DPPH solution; ${ }^{d}$ in millimolar Trolox ${ }^{\circledR}$ antioxidant equivalents (TEAA)/g of dry plant material. ${ }^{\mathrm{e}}$ Inhibition ratio of LA-peroxidation after incubation with the final antioxidant concentration of $1.50 \mathrm{mg} / \mathrm{mL}$ for the plant materials or $0.20 \mathrm{mg} / \mathrm{mL}$ for the standards.

\section{Results and Discussion}

\subsection{Phenolic profile of the analysed Sorbus tissues}

The total phenolic content (TPC) of the Sorbus extracts was determined by the Folin-Ciocalteu (FC) photometric assay. In this method, a mixture of phosphotungstic and phosphomolybdic acids is reduced under alkaline conditions to blue oxides of tungsten and molybdenum upon phenol oxidation [15]. The reaction is commonly used to obtain a crude estimate of TPC as gallic acid equivalents (GAE), but it can also be considered as an indirect measure of antioxidant activity because of the basic redox mechanism, similar to that occurring in other antioxidant methods $[11,15]$.

As shown in Table 2, the majority of the tested Sorbus tissues exhibited high levels of TPC ranging from 8.08 to $12.31 \% \mathrm{dw}$ of GAE, with the average value for all samples of $8.81 \% \mathrm{GAE}$, and with the highest content found for the leaves of $S$. wilfordii (sample 13, $12.31 \pm 0.32 \%$ GAE). In ten samples $(\mathbf{1}, \mathbf{3}, \mathbf{1 1}, \mathbf{1 3}, \mathbf{1 6}-18, \mathbf{2 1}, \mathbf{2 3}, \mathbf{2 4})$ the TPC was not less than 10\% GAE. For different plant tissues derived from the same Sorbus species, the TPC level was remarkably higher in the inflorescences than in the leaves. The single exception was S. gracilis, whose inflorescences and leaves (samples 16 and 17) exhibited similar but still statistically different TPC values (11.06 and 10.72\% GAE, $p<0.05$ ).

It is evident that the TPC value determined by the FC assay does not give a full picture of the real phenolic constituents in plant extracts. Thus, for verification of the phenolic levels in Sorbus, further determinations of the main phenolic groups were performed. 
Table 2. Total phenolic content, total content of chlorogenic acid isomers, and total proanthocyanidin content in Sorbus extracts. ${ }^{\text {a }}$

\begin{tabular}{|c|c|c|c|c|c|}
\hline \multirow{2}{*}{\multicolumn{2}{|c|}{ Sample No. }} & \multirow{3}{*}{$\begin{array}{c}\text { Total phenols }(\mathbf{G A E}, \mathbf{\%})^{\mathbf{b}} \\
10.02 \pm 0.22^{\mathrm{A}}\end{array}$} & \multicolumn{2}{|c|}{ Caffeoylquinic acids ${ }^{\mathrm{c}}(\%)$} & \multirow{3}{*}{$\begin{array}{c}\begin{array}{c}\text { Proanthocyanidins } \\
\mathbf{( C y E , ~ \% ) ~}^{\mathbf{d}}\end{array} \\
5.94 \pm 0.12^{\mathrm{A}}\end{array}$} \\
\hline & & & \multirow{2}{*}{$\frac{\text { NChA }}{0.74 \pm 0.01^{\mathrm{A}}}$} & \multirow{2}{*}{$\begin{array}{c}\text { ChA } \\
2.27 \pm 0.01^{\mathrm{A}}\end{array}$} & \\
\hline CL1: & 1. & & & & \\
\hline & 3. & $11.32 \pm 0.03^{\mathrm{B}}$ & $0.70 \pm 0.01^{\mathrm{B}}$ & $2.48 \pm 0.02^{\mathrm{B}, \mathrm{C}}$ & $7.67 \pm 0.05^{\mathrm{B}}$ \\
\hline & 17. & $10.72 \pm 0.16^{\mathrm{C}}$ & $0.03 \pm 0.01^{\mathrm{C}}$ & $0.93 \pm 0.01^{\mathrm{D}, \mathrm{E}}$ & $6.56 \pm 0.07^{\mathrm{C}}$ \\
\hline & 18. & $10.08 \pm 0.11^{\mathrm{A}, \mathrm{D}}$ & $0.45 \pm 0.02^{\mathrm{D}}$ & $3.13 \pm 0.06^{\mathrm{F}}$ & $7.14 \pm 0.11^{\mathrm{D}}$ \\
\hline & 11. & $11.67 \pm 0.16^{\mathrm{E}}$ & $1.26 \pm 0.02^{\mathrm{E}}$ & $3.85 \pm 0.06^{\mathrm{G}}$ & $6.40 \pm 0.12^{\mathrm{C}}$ \\
\hline & 21. & $11.67 \pm 0.05^{\mathrm{E}}$ & $1.98 \pm 0.01^{\mathrm{F}}$ & $2.05 \pm 0.02^{\mathrm{H}}$ & $6.86 \pm 0.12^{\mathrm{E}}$ \\
\hline & 16. & $11.06 \pm 0.16^{\mathrm{F}}$ & $0.19 \pm 0.01^{\mathrm{G}}$ & $3.31 \pm 0.03^{\mathrm{I}}$ & $6.54 \pm 0.16^{\mathrm{C}}$ \\
\hline & 23. & $10.90 \pm 0.26^{\mathrm{C}, \mathrm{F}}$ & $0.22 \pm 0.01^{\mathrm{H}}$ & $1.63 \pm 0.02^{\mathrm{J}}$ & $5.89 \pm 0.04^{\mathrm{A}}$ \\
\hline & 9. & $9.29 \pm 0.14^{\mathrm{G}}$ & $0.76 \pm 0.01^{\mathrm{A}}$ & $3.92 \pm 0.02^{\mathrm{G}}$ & $5.98 \pm 0.21^{\mathrm{A}}$ \\
\hline & 13. & $12.31 \pm 0.32^{\mathrm{H}}$ & $0.13 \pm 0.01^{\mathrm{I}}$ & $2.58 \pm 0.02^{\mathrm{B}}$ & $5.31 \pm 0.04^{\mathrm{F}}$ \\
\hline \multirow[t]{8}{*}{ CL2: } & 2. & $8.23 \pm 0.06^{\mathrm{I}, \mathrm{J}}$ & $0.51 \pm 0.01^{\mathrm{J}}$ & $1.90 \pm 0.08^{\mathrm{K}}$ & $3.59 \pm 0.09^{\mathrm{G}, \mathrm{H}}$ \\
\hline & 7. & $8.44 \pm 0.08^{\mathrm{J}}$ & $1.10 \pm 0.04^{\mathrm{K}}$ & $2.81 \pm 0.09^{\mathrm{L}}$ & $2.90 \pm 0.06^{\mathrm{I}}$ \\
\hline & 10. & $8.08 \pm 0.25^{\mathrm{I}}$ & $0.05 \pm 0.01^{\mathrm{C}}$ & $0.79 \pm 0.01^{\mathrm{E}, \mathrm{M}}$ & $3.58 \pm 0.09^{\mathrm{G}, \mathrm{H}}$ \\
\hline & 12. & $8.10 \pm 0.09^{\mathrm{I}}$ & $0.19 \pm 0.01^{\mathrm{G}}$ & $2.10 \pm 0.01^{\mathrm{H}}$ & $4.03 \pm 0.09^{\mathrm{J}}$ \\
\hline & 14. & $8.22 \pm 0.40^{\mathrm{I}, \mathrm{J}}$ & $0.42 \pm 0.01^{\mathrm{L}}$ & $4.17 \pm 0.12^{\mathrm{N}}$ & $3.79 \pm 0.16^{\mathrm{H}, \mathrm{K}}$ \\
\hline & 5. & $8.47 \pm 0.21^{\mathrm{J}}$ & $0.60 \pm 0.01^{\mathrm{M}}$ & $2.36 \pm 0.02^{\mathrm{A}, \mathrm{C}}$ & $5.68 \pm 0.10^{\mathrm{L}, \mathrm{M}}$ \\
\hline & 22. & $9.87 \pm 0.11^{\mathrm{A}}$ & $0.53 \pm 0.01^{\mathrm{J}}$ & $1.97 \pm 0.02^{\mathrm{H}, \mathrm{K}}$ & $5.81 \pm 0.09^{\mathrm{A}, \mathrm{M}}$ \\
\hline & 24. & $10.18 \pm 0.17^{\mathrm{D}}$ & $0.22 \pm 0.01^{\mathrm{H}}$ & $2.61 \pm 0.02^{\mathrm{B}}$ & $5.56 \pm 0.08^{\mathrm{L}}$ \\
\hline \multirow[t]{6}{*}{ CL3: } & 4. & $6.26 \pm 0.19^{\mathrm{K}}$ & $0.12 \pm 0.01^{\mathrm{I}, \mathrm{O}}$ & $0.67 \pm 0.01^{\mathrm{M}, \mathrm{O}}$ & $3.93 \pm 0.03^{\mathrm{J}, \mathrm{K}}$ \\
\hline & 20. & $5.78 \pm 0.12^{\mathrm{L}}$ & $0.37 \pm 0.01^{\mathrm{N}}$ & $1.25 \pm 0.01^{\mathrm{P}}$ & $4.02 \pm 0.05^{\mathrm{J}}$ \\
\hline & 8. & $6.47 \pm 0.09^{\mathrm{K}}$ & $0.04 \pm 0.01^{\mathrm{C}}$ & $1.85 \pm 0.01^{\mathrm{K}}$ & $3.66 \pm 0.09^{\mathrm{G}}$ \\
\hline & 6. & $4.23 \pm 0.15^{\mathrm{M}}$ & $0.36 \pm 0.01^{\mathrm{N}}$ & $1.24 \pm 0.01^{\mathrm{P}}$ & $1.47 \pm 0.04^{\mathrm{N}}$ \\
\hline & 15. & $5.07 \pm 0.02^{\mathrm{N}}$ & $0.10 \pm 0.02^{\circ}$ & $1.02 \pm 0.01^{\mathrm{D}}$ & $1.96 \pm 0.09^{\mathrm{O}}$ \\
\hline & 19. & $4.89 \pm 0.07^{\mathrm{N}}$ & $0.05 \pm 0.01^{\mathrm{C}}$ & $0.56 \pm 0.01^{\mathrm{O}}$ & $1.48 \pm 0.05^{\mathrm{N}}$ \\
\hline
\end{tabular}

${ }^{\mathrm{a}}$ Results are mean values of triplicate analyses calculated per $\mathrm{dw}$ of the plant material \pm S.D. Different superscripts (capitals) in each column indicate significant differences in the mean values at $p<0.05$. Sample codification as in Table 1. CL1-CL2, groups obtained after cluster analysis. ${ }^{\mathrm{b}}$ Total phenolic content expressed in GAE, gallic acid equivalents. ${ }^{\mathrm{c}}$ Content of chlorogenic acid isomers quantified by HPLC: NChA, neochlorogenic acid; ChA, chlorogenic acid. ${ }^{\mathrm{d}}$ Total proanthocyanidin content expressed in $\mathrm{CyE}$, cyanidin chloride equivalents.

As shown in Tables 2 and 3, the predominant components in the majority of the extracts were proanthocyanidins, followed by caffeoylquinic acids and flavonoids. In three samples (6, 7, and 14), the sum of caffeoylquinic acid isomers (chlorogenic (ChA) and neochlorogenic (NChA) acids) was greater. The tested plant materials showed a wide range of total proanthocyanidin content $(1.47-7.67 \%$ $\mathrm{dw}$ calculated as cyanidin equivalents, CyE), sum of caffeoylquinic acid isomers $(0.61-5.11 \% \mathrm{dw})$, and total content of flavonoid aglycones $(0.121-1.322 \% \mathrm{dw})$. 
Table 3. Total content of flavonoid aglycones in Sorbus extracts. ${ }^{\text {a }}$

\begin{tabular}{|c|c|c|c|c|}
\hline \multirow{2}{*}{\multicolumn{2}{|c|}{ Sample No. }} & \multicolumn{3}{|c|}{ Flavonoid aglycones ${ }^{\mathrm{d}} \mathbf{( \% )}$} \\
\hline & & QU & KA & SX \\
\hline CL1: & $\begin{array}{l}1 . \\
3 . \\
17 . \\
18 . \\
11 . \\
21 . \\
16 . \\
23 . \\
9 . \\
13 .\end{array}$ & $\begin{array}{c}1.048 \pm 0.034^{\mathrm{A}} \\
0.400 \pm 0.014^{\mathrm{B}} \\
0.113 \pm 0.001^{\mathrm{C}} \\
0.384 \pm 0.028^{\mathrm{B}, \mathrm{K}} \\
0.839 \pm 0.008^{\mathrm{D}, \mathrm{E}} \\
0.266 \pm 0.014^{\mathrm{F}} \\
0.194 \pm 0.006^{\mathrm{G}, \mathrm{H}} \\
0.382 \pm 0.023^{\mathrm{B}, \mathrm{K}} \\
0.422 \pm 0.008^{\mathrm{B}, \mathrm{J}} \\
0.878 \pm 0.015^{\mathrm{E}, \mathrm{I}}\end{array}$ & $\begin{array}{c}0.084 \pm 0.002^{\mathrm{A}} \\
0.039 \pm 0.001^{\mathrm{B}} \\
0.008 \pm 0.001^{\mathrm{C}} \\
0.021 \pm 0.001^{\mathrm{D}} \\
0.059 \pm 0.001^{\mathrm{E}, \mathrm{F}} \\
0.024 \pm 0.003^{\mathrm{D}} \\
0.012 \pm 0.001^{\mathrm{C}} \\
0.263 \pm 0.006^{\mathrm{G}} \\
0.050 \pm 0.003^{\mathrm{F}} \\
0.046 \pm 0.001^{\mathrm{B}, \mathrm{F}}\end{array}$ & $\begin{array}{c}0.190 \pm 0.002^{\mathrm{A}} \\
0.017 \pm 0.001^{\mathrm{B}} \\
\text { nd } \\
0.048 \pm 0.001^{\mathrm{C}} \\
0.070 \pm 0.002^{\mathrm{D}} \\
0.050 \pm 0.005^{\mathrm{C}} \\
0.072 \pm 0.003^{\mathrm{D}} \\
\text { nd } \\
0.045 \pm 0.003^{\mathrm{C}} \\
\text { nd }\end{array}$ \\
\hline CL2: & $\begin{array}{l}2 . \\
7 . \\
10 . \\
12 . \\
14 . \\
5 . \\
22 . \\
24 .\end{array}$ & $\begin{array}{c}0.903 \pm 0.003^{\mathrm{I}} \\
0.790 \pm 0.020^{\mathrm{D}} \\
0.470 \pm 0.004^{\mathrm{J}} \\
0.474 \pm 0.012^{\mathrm{J}} \\
0.805 \pm 0.017^{\mathrm{D}} \\
0.341 \pm 0.005^{\mathrm{K}} \\
0.247 \pm 0.007^{\mathrm{F}, \mathrm{G}} \\
0.566 \pm 0.031^{\mathrm{L}}\end{array}$ & $\begin{array}{c}0.157 \pm 0.005^{\mathrm{H}} \\
0.117 \pm 0.001^{\mathrm{I}, \mathrm{J}} \\
0.011 \pm 0.001^{\mathrm{C}} \\
0.035 \pm 0.001^{\mathrm{B}} \\
0.058 \pm 0.001^{\mathrm{E}, \mathrm{F}} \\
0.062 \pm 0.001^{\mathrm{E}} \\
0.106 \pm 0.002^{\mathrm{K}} \\
0.306 \pm 0.007^{\mathrm{L}}\end{array}$ & $\begin{array}{c}\text { nd } \\
\text { nd } \\
\text { nd } \\
\text { nd } \\
0.127 \pm 0.003^{\mathrm{E}} \\
0.145 \pm 0.002^{\mathrm{F}} \\
\text { nd } \\
\text { nd }\end{array}$ \\
\hline CL3: & $\begin{array}{l}4 . \\
20 . \\
8 . \\
6 . \\
15 . \\
19 .\end{array}$ & $\begin{array}{c}0.123 \pm 0.004^{\mathrm{C}, \mathrm{H}} \\
0.525 \pm 0.006^{\mathrm{L}} \\
0.460 \pm 0.019^{\mathrm{J}} \\
0.217 \pm 0.009^{\mathrm{G}} \\
0.163 \pm 0.006^{\mathrm{C}, \mathrm{H}} \\
0.270 \pm 0.012^{\mathrm{F}}\end{array}$ & $\begin{array}{c}0.030 \pm 0.001^{\mathrm{B}, \mathrm{D}} \\
0.113 \pm 0.002^{\mathrm{J}, \mathrm{K}} \\
0.039 \pm 0.001^{\mathrm{B}} \\
0.125 \pm 0.009^{\mathrm{I}} \\
0.011 \pm 0.001^{\mathrm{C}} \\
0.023 \pm 0.001^{\mathrm{D}}\end{array}$ & $\begin{array}{l}\text { nd } \\
\text { nd } \\
\text { nd } \\
\text { nd } \\
\text { nd } \\
\text { nd }\end{array}$ \\
\hline
\end{tabular}

${ }^{\mathrm{a}}$ Results are mean values of triplicate analyses calculated per $\mathrm{dw}$ of the plant material \pm S.D. Different superscripts (capitals) in each column indicate significant differences in the mean values at $p<0.05$. Sample codification as in Table 1. CL1-CL2, groups obtained after cluster analysis. ${ }^{\mathrm{b}}$ Content of flavonoid aglycones quantified by HPLC: QU, quercetin; KA, kaempferol; SX, sexangularetin; nd - not detected.

The highest levels of proanthocyanidins were found for the inflorescences of S. pohuashanensis (sample 3, $7.67 \pm 0.05 \% \mathrm{CyE}$ ) and S. sitchensis (sample 18, $7.14 \pm 0.11 \% \mathrm{CyE}$ ). The highest content of caffeoylquinic acid isomers was found in the inflorescences of S. decora (sample 11, 5.11 $\pm 0.08 \%$ ). With the exception of sample 21 (inflorescences of S. koehneana), the dominant caffeoylquinic isomer in all other tested samples was ChA, with the levels constituting $71-97 \%$ of the sum of both quantified isomers. In sample 21, the levels of ChA and NChA were similar and reached about $2 \% \mathrm{dw}$ each. Of the flavonoids, quercetin was the predominant aglycone with the levels varying widely among the assayed samples $(0.113-1.048 \% \mathrm{dw})$. Quercetin was accompanied by kaempferol $(0.011-0.306 \% \mathrm{dw})$ in the leaf samples, and by kaempferol $(0.021-0.084 \% \mathrm{dw})$ and sexangularetin $(0.017-0.190 \% \mathrm{dw})$ in the inflorescences. The highest flavonoid content was found for the inflorescences of $S$. aucuparia (sample 1, 1.322\% dw).

For the majority of samples, the total content of the particular phenolic groups (TPh, proanthocyanidins + caffeoylquinic acids + flavonoid aglycones) was consistent with the TPC level expressed in GAE, which is in accordance with the results of our earlier study of three Sorbus species [3]. This correlation was statistically significant at $p<0.001$, and was characterised by high correlation and determination coefficients $r\left(R^{2}\right)=0.8551(0.7312)$. Remarkable differences in these contents were 
observed only for six leaf samples $(\mathbf{1 0}, \mathbf{1 3}, \mathbf{1 5}, \mathbf{1 7}, \mathbf{1 9}$, and 23), in which the TPC values were significantly higher than the TPh levels. This discrepancy could be caused by the presence of some unquantified phenolic metabolites, such as simple phenolic acids, or by the presence of some interfering substances that are reactive in the FC assay, such as sugars or ascorbic acid [11,15]. If the six above-mentioned cases were excluded, the correlation between TPC and TPh levels was especially high $\left(r\left(R^{2}\right)=0.9181(0.8429), p<0.001\right)$. This is clear evidence that the listed groups of phenolic compounds are the main phenolic metabolites present in the tested Sorbus samples and that they are also the most important phenolic determinants of the redox activity of these samples.

\subsection{Antioxidant activity of the extracts from Sorbus tissues}

Given the differences in the basic reaction mechanisms among the wide number of available test systems, an approach involving at least two different assays is highly advisable to fully characterise the antioxidant properties of plant extracts $[11,15]$. On this basis, the in vitro antioxidant activity of Sorbus tissues was assayed using two complementary tests: the DPPH free radical scavenging method (the widely used system involving the single electron transfer (SET) reaction) and inhibition of the AAPHinduced linoleic acid (LA) peroxidation test (involving the hydrogen atom transfer (HAT) mechanism, a more physiologically and food-relevant system).

The antioxidant results are summarised in Table 1. A significant $(p<0.001)$ correlation was found between the results of the two methods, characterised by the coefficients of correlation $(r=-0.8089)$ and determination $\left(R^{2}=0.6543\right)$, suggesting that the analysed Sorbus extracts utilise both the HAT and SET reaction mechanisms. Although these $R$-values are both quite high, they were lower than those observed for the correlations between the DPPH and FC assay and also between the LA-peroxidation test and the FC method (Table 4).

Table 4. Correlation $(r)$ and determination $\left(R^{2}\right)$ coefficients between different parameters of antioxidant capacity of Sorbus extracts and the content of phenolic compounds.

\begin{tabular}{lcc}
\hline $\boldsymbol{r}\left(\boldsymbol{R}^{2}\right)$ & DPPH EC $_{\mathbf{5 0}}(\boldsymbol{\mu g} \mathbf{m} \mathbf{m L})^{\mathbf{c}}$ & ${\text { LA peroxidation }(\% \text { inhibition })^{\mathbf{c}}}^{\mathbf{c}}$ \\
\hline TPC $(\mathrm{GAE}, \%)^{\mathrm{a}}$ & $-0.9535(0.9092)^{*}$ & $0.8664(0.7506)^{*}$ \\
TPh $(\%)^{\mathrm{b}}$ & $-0.8525(0.7267)^{*}$ & $0.7377(0.5442)^{*}$ \\
Proanthocyanidins (CyE, \%) & $-0.8007(0.6411)^{*}$ & $0.7456(0.5559)^{*}$ \\
Caffeoylquinic acids (ChA+NChA, \%) & $-0.6238(0.3891)^{* *}$ & $0.4998(0.2498)^{* * *}$ \\
Flavonoid aglycones (\%) & $-0.4248(0.1804)^{* * *}$ & $0.2297(0.0528)$ \\
\hline
\end{tabular}

${ }^{\mathrm{a}} \mathrm{TPC}$, total phenolic content determined by the FC method expressed in GAE, gallic acid equivalents. ${ }^{\mathrm{b}} \mathrm{TPh}$, total phenolic content expressed as the sum of proanthocyanidins, caffeoylquinic acids and flavonoid aglycones. ${ }^{c}$ Significance levels: ${ }^{*} p<0.001 ; * * p<0.01$; $* * * p<0.05$.

This lower correlation might be attributed to the different reaction mechanisms and was also observed for other plant extracts [16]. Analysis of the scatter plot (Figure 1) for the DPPH and LAperoxidation tests showed that the samples exhibit differences in antioxidant results between the two assay methods and that they could be distributed in three main groups. This hypothesis was verified statistically by partitional clustering ( $k$-means method). The first cluster (CL1) grouped ten samples (1, 
$3,17,18,11,21,16,23,9$, and 13) exhibiting the highest antioxidant capacities in both systems with a mean scavenging efficiency for the $\mathrm{DPPH}$ radical of $\mathrm{EC}_{50}=18.56 \pm 2.57 \mu \mathrm{g} / \mathrm{mL}$ $($ TEAA $=0.71 \pm 0.09 \mathrm{mmol} / \mathrm{g}$ ) and a mean LA-inhibition in the peroxidation test of $72.73 \pm 4.28 \%$. The eight samples grouped in the second cluster CL2 $(\mathbf{2}, \mathbf{7}, \mathbf{1 0}, \mathbf{1 2}, \mathbf{1 4}, \mathbf{5}, \mathbf{2 2}$, and 24) demonstrated relatively high scavenging capacities (mean $\mathrm{EC}_{50}=25.98 \pm 2.08 \mu \mathrm{g} / \mathrm{mL}$, TEAA $=0.51 \pm 0.04 \mathrm{mmol} / \mathrm{g}$ ) and moderate inhibition of LA peroxidation (mean value $58.26 \pm 2.94 \%$ ). The samples with the lowest antioxidant activity $\left(4,8,20,6,15\right.$, and 19) constituted the third cluster (CL3), with a mean $\mathrm{EC}_{50}$ value of $49.32 \pm 7.07 \mu \mathrm{g} / \mathrm{mL}($ TEAA $=0.26 \pm 0.04 \mathrm{mmol} / \mathrm{g})$ and a mean inhibition of LA-peroxidation of $51.16 \pm 4.86 \%$.

Figure 1. Scatter diagram of the correlation between parameters of antioxidant capacity of Sorbus extracts measured by the DPPH test and LA-peroxidation assay.

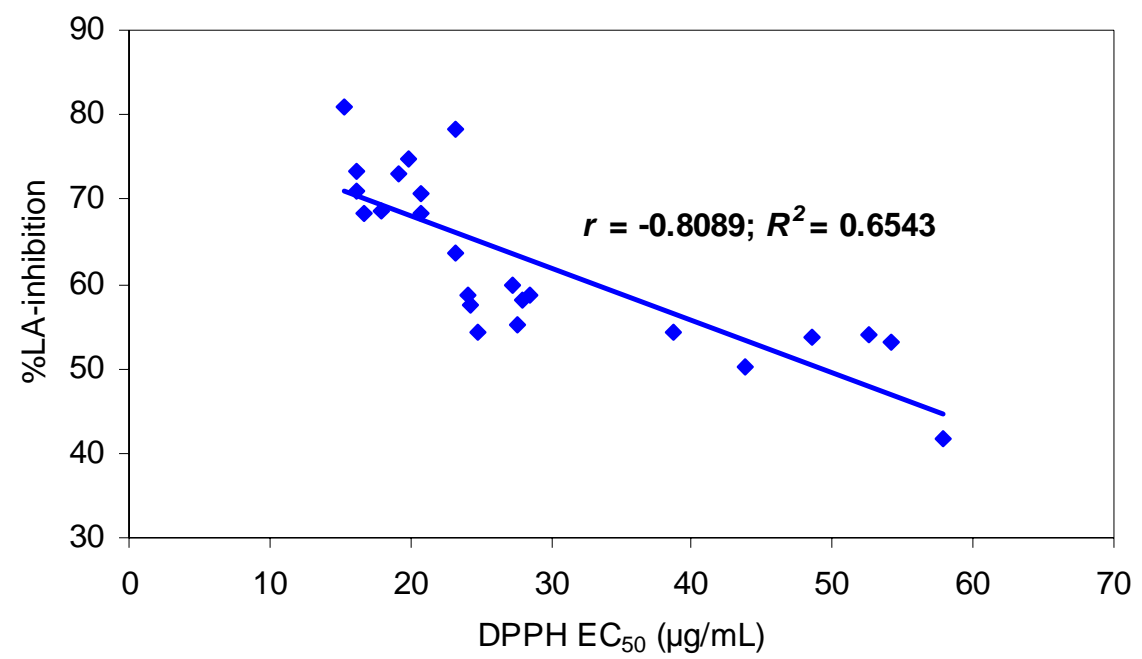

There are limited data in the literature $[13,14]$ with which it would be possible to easily compare our antioxidant results, given the differences in the assay protocols. According to these systematic screening studies, only about $20 \%$ of known plant materials have high or extremely high antioxidant activity as measured by the DPPH method, and exhibit TEAA values in the range $0.25-1.00 \mathrm{mmol} / \mathrm{g}$ $\mathrm{dw}$ (14\% of plants) or even higher (6\%). As shown in Table 1, all analysed Sorbus samples were found to have high (clusters CL2 and CL3) and very high antioxidant activity (cluster CL1). It is noteworthy that the majority of plant tissues previously reported to have extremely high antioxidant activity (TEAA $\geq 1.00 \mathrm{mmol} / \mathrm{g} \mathrm{dw}$ ), such as gum of Acacia catechu, seeds of Magnifera indica, bark of Myrica nagi, pericarp of Punica granatum, and galls of Rhus succedanea, contained hydrolysable tannins (gallotaninns) as the main active components [14]. Gallotannins are known as potent scavengers of the DPPH radical [17], but they could also be hepatotoxic in internal applications due to the hydrolytic liberation of gallic acid [18]. As described in Section 2.1, the main antioxidant constituents of the studied Sorbus plants are proanthocyanidins, isomers of chlorogenic acid and flavonols (quercetin derivatives), compounds that are considered to be safe in rational therapy [19-21]. Potential safety issues exist only if megadoses of these phenolics are consumed daily [19,20]. Therefore, with their high activity and high total phenolic content, the analysed Sorbus tissues appear to be very promising and potent sources of safe natural antioxidants. 


\subsection{Relationships among the estimates of antioxidant capacities obtained from the DPPH and LA-} peroxidation assays, and phenolic contents

A linear regression analysis was performed for all experimental data $(n=24)$ to study the relationships among the estimated values of antioxidant activity and phenolic content. The results (Table 4) revealed a strong and significant correlation $(|r|>0.86, p<0.001)$ between the antioxidant results obtained by the two methods and the total phenolic content measured by the FC method.

Thus, the levels of TPC expressed in GAE could be considered to be an important indicator of antioxidant capacity, and may be applied to preliminarily screen plant extracts for use as natural sources of antioxidants. The high correlation observed between the results of both antioxidant tests and the total phenolic content expressed as the sum of proanthocyanidins, caffeoylquinic acids and flavonoids $(\mathrm{TPh})$ confirmed that these phenolic groups were synergistic determinants of the tested activity. Of the three analysed groups, proanthocyanidins could be considered to be primarily responsible for the estimated antioxidant activity, followed by the chlorogenic acid isomers and flavonoid aglycones. These results are in accordance with published reports on the potent activity of proanthocyanidins, chlorogenic acid, and flavonoids (especially quercetin derivatives) in numerous antioxidant in vitro test systems [17,22,23]. On the other hand, the observed low impact of flavonoids on the antioxidant activity conflicts with the results of our earlier study of Sorbus species [3]. This discrepancy could be explained by the low number of samples $(n=9)$ and close genetic relationship between the three species tested previously (two parental and their descendant hybrid species). It is also known that the antioxidant activity of flavonoids is strongly structurally dependent [17], and thus structural differences between the real flavonoid constituents, which exist in the Sorbus extracts mostly in the form of glycosides [10], and the aglycones estimated after acid hydrolysis, could bring about the low correlation found in the present study.

\subsection{Hierarchical cluster analysis of the Sorbus samples}

An agglomerative hierarchical cluster analysis (CA) was performed for all of the experimental data, taking the Euclidean distance as the metric and the complete linkage method as the amalgamation rule. The results were in accordance with those obtained by partitional clustering (Section 2.2). As presented in the dendrogram (Figure 2), three main clusters were found, corresponding to the three levels of antioxidant capacities and phenolic contents of the analysed Sorbus samples.

The ten samples that grouped in the cluster CL1 (inflorescences of S. aucuparia, S. pohuashanensis, S. decora, S. koehneana, S. commixta, S. gracilis, and S. sitchensis, as well as the leaves of S. wilfordii, S. pogonopetala, and $S$. gracilis) were characterised by the highest antioxidant capacities (see section 2.2), TPC level (mean TPC $=10.90 \pm 0.91 \%$ GAE), total proanthocyanidin contents (mean level $=6.43 \pm 0.69 \% \mathrm{CyE}$ ) and contents of caffeoylquinic acids (mean level = 3.26 $\pm 1.24 \%$ ). Therefore, these samples could be considered to have the greatest potential as valuable and costeffective sources of natural phenolic antioxidants among the studied Sorbus samples.

By converting the original average value of $\mathrm{EC}_{50}$ for the DPPH test $(18.76 \pm 2.65 \mu \mathrm{g} / \mathrm{mL})$ to $\mu \mathrm{g}$ phenolics/mL using the mean TPC value for the cluster CL1, we obtain the recalculated value of $\mathrm{EC}_{50}=2.05 \mu \mathrm{g}$ phenolics $/ \mathrm{mL}$. 
Figure 2. Dendrogram built by hierarchical cluster analysis with all of the variables using the complete linkage method and Euclidean squared distance. Codification is given in Table 1.

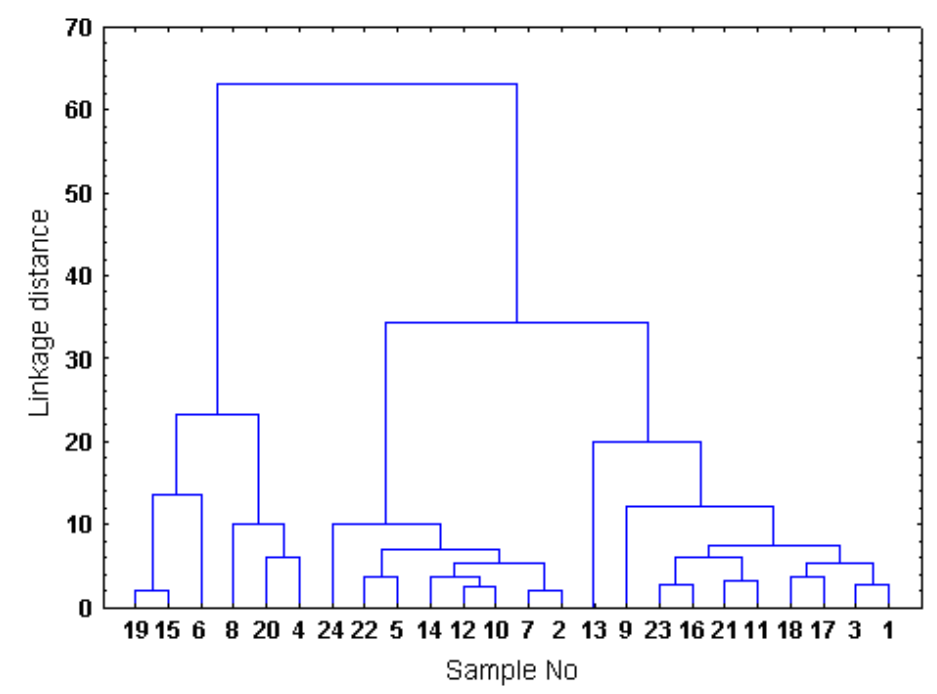

The standards of quercetin and Trolox $^{\circledR}$ assayed simultaneously exhibited $\mathrm{EC}_{50}$ values of $1.44 \pm 0.05$ and $3.27 \pm 0.10 \mu \mathrm{g} / \mathrm{mL}$, respectively. According to the literature, the antioxidant activity of quercetin and trolox is remarkably higher than that of the synthetic antioxidants that are used industrially, such as BHA and BHT [24,25]. We believe that this is convincing evidence of the potent antioxidant activity of the ten Sorbus samples grouped in the cluster CL1. Thus, these samples appear to be good candidates for in vivo studies of antioxidant protection with high potential for use as possible substitutes for the currently used synthetic antioxidants.

\section{Experimental}

\subsection{Plant material}

Samples of inflorescences and leaves of the 16 studied Sorbus species were collected and authenticated in June 2009 in the Arboretum $\left(51^{\circ} 49^{\prime} \mathrm{N}, 1^{\circ} 53^{\prime} \mathrm{E}\right)$, Forestry Experimental Station of Warsaw University of Life Sciences (SGGW) in Rogów (Poland). Voucher specimens (Table 5) were deposited in the herbarium of the Department of Pharmacognosy, Medical University of Łódź, Poland. The studied samples are listed in Table 1.

Table 5. Voucher specimen numbers of the studied Sorbus species.

\begin{tabular}{llll}
\hline Scientific name & $\begin{array}{l}\text { Voucher specimen } \\
\text { no. }\end{array}$ & Scientific name & $\begin{array}{l}\text { Voucher } \\
\text { specimen no. }\end{array}$ \\
\hline Sorbus aucuparia L. & KFG/HB/07001- & Sorbus sambucifolia (Cham. \& & $\begin{array}{l}\text { KFG/HB/08008- } \\
\text { SSAM }\end{array}$ \\
& SAUC & Schltdl.) M. Roem. & \\
Sorbus pohuashanensis (Hance) & KFG/HB/07002- & & \\
Hedl. & SPOH & Sorbus gracilis (Sieb. \& Zucc.) K. KFG/HB/07006- \\
Sorbus scalaris Koehne & KFG/HB/08005- & Koch & SGRA \\
& SSCA & Sorbus sitchensis M. Roem. & KFG/HB/08009-SSIT \\
Sorbus prattii Koehne var. prattii & KFG/HB/08006- & & \\
& SPRA & & \\
\hline
\end{tabular}


Table 5. Cont.

\begin{tabular}{llll}
\hline Sorbus americana Marsh. & KFG/HB/07003- & Sorbus cashmiriana Hedl. & KFG/HB/07007- \\
& SAME & & SCAS \\
Sorbus commixta Hedl. & KFG/HB/07004- & Sorbus koehneana C.K. Schneid. & KFG/HB/07008- \\
& SCOM & SKOE & KFG/HB/07009- \\
Sorbus decora (Sarg.) C.K. & KFG/HB/08007- & Sorbus pogonopetala Koehne & SPOG \\
$\begin{array}{l}\text { Schneid. } \\
\text { Sorbus wilfordii Koehne }\end{array}$ & SDEC & & KFG/HB/08010- \\
& KFG/HB/07005-SWIL Sorbus setschwanensis (C.K. & SSET \\
\hline
\end{tabular}

\subsection{Chemicals and instrumentation}

HPLC or GC grade purity reagents and standards, such as 2,2-diphenyl-1-picryl hydrazyl (DPPH); 2,2'-azobis-(2-amidinopropane) dihydrochloride (AAPH); ( \pm )-6-hydroxy-2,2,7,8-tetramethylchroman2-carboxylic acid $\left(\right.$ Trolox $\left.{ }^{\circledR}\right)$; linoleic acid; chlorogenic acid hemihydrate; gallic acid monohydrate; and quercetin trihydrate were purchased from Sigma-Aldrich Inc.(Germany/USA). HPLC grade solvents, $\mathrm{MeCN}$ and $\mathrm{H}_{3} \mathrm{PO}_{4}$ were used for HPLC analyses and were obtained from Merck (Germany). For other analyses redistilled water and analytical grade chemicals and solvents (POCh S.A., Poland) were used.

Absorbance was measured using a Lambda 25 spectrophotometer (Perkin-Elmer, USA), in $10 \mathrm{~mm}$ quartz cuvettes. Samples were incubated in a constant temperature using a BD 23 incubator (Binder, Germany). HPLC analyses were carried out on a Waters 600E Multisolvent Delivery System (Waters Co., USA) with a PDA detector (W 996), a $20 \mu \mathrm{L}$ sample injector (Rheodyne $7725 \mathrm{i}$ ), and a LC workstation equipped with Waters Empower software for data collection and acquisition. A C18 Lichrosphere 100 column $(5 \mu \mathrm{m}, 250 \mathrm{~mm} \times 4.6 \mathrm{~mm}$, i.d.) (Merck) guarded by a C18 Hypersil ODS pre-column ( $5 \mu \mathrm{m}, 4 \times 4 \mathrm{~mm}$, i.d.; Agilent Technologies, USA) was used. Constant temperature of the column was maintained using a Jetstream Plus 5480 termostat (Peltier, Austria). Before injection to HPLC system, samples were filtered through a PTFE syringe filter (13 mm, $0.2 \mu \mathrm{m}$, Whatman, USA).

\subsection{Preparation of plant extracts for testing antioxidant activity and phenolic profile}

The samples of plant material were air-dried under normal conditions, powdered with an electric grinder, and sieved through a $0.315-\mathrm{mm}$ sieve. An accurately weighed mass $(2.0 \mathrm{~g}$ for the LA-peroxidation test, and 100-250 mg depending on the plant tissue analysed, for the other assays) was refluxed first for $30 \mathrm{~min}$ with 70\% (v/v) aqueous $\mathrm{MeOH}(30 \mathrm{~mL})$ [4], and then twice for $15 \mathrm{~min}$ with more of the same solvent $(20 \mathrm{~mL})$. The obtained extracts were combined, filtered and diluted with $\mathrm{MeOH}$ to $100 \mathrm{~mL}$ to give the test extracts (TE).

\subsection{DPPH free radical-scavenging test}

The scavenging activity was determined based on the method of Brand-Williams, Cuvelier, and Berset [26] with slight modifications. The DPPH working solution $(35.5 \mathrm{mg} / \mathrm{L}, 90 \mu \mathrm{M})$ was prepared in methanol and equilibrated everyday to the absorbance of the negative control of $0.700 \pm 0.030$ at $517 \mathrm{~nm}$. It was prepared by mixing the DPPH working solution $(2 \mathrm{~mL})$ with methanol $(1 \mathrm{~mL})$. Five different concentrations of all extracts and standards were prepared in methanol-water $(70: 30, \mathrm{v} / \mathrm{v})$. An aliquot of the sample $(1 \mathrm{~mL})$ was added to the equilibrated DPPH working solution $(2 \mathrm{~mL})$ and vigorously shaken. After $60 \mathrm{~min}$ of incubation in screw-cap vials at room temperature in the dark, the 
decrease in the absorbance was measured at $517 \mathrm{~nm}$. The mixtures of the sample $(1 \mathrm{~mL})$ and methanol $(2 \mathrm{~mL})$ were used as blanks. The concentration of the analyte (standard or plant material used for extract preparation) in the reaction medium (in $\mu \mathrm{g} / \mathrm{mL}$ ) was plotted against the percentage of remaining DPPH using the DPPH calibration curve, and the $\mathrm{EC}_{50}$ value was calculated. The standards of quercetin and trolox were used as positive controls. The activity of the plant materials was then expressed in terms of trolox (TEAA) equivalent antioxidant activity in $\mathrm{mmol} / \mathrm{g} \mathrm{dw}$.

\subsection{Linoleic acid (LA) peroxidation test}

The ability of TE to inhibit AAPH-induced LA-peroxidation was assayed according to the method of Azuma et al. [27] with some modifications. An aliquot of TE $(0.30 \mathrm{~mL})$ was placed in a screw-cap vial and mixed with $1.3 \%(\mathrm{w} / \mathrm{v}) \mathrm{LA}$ in $\mathrm{MeOH}(1.40 \mathrm{~mL}), 0.2 \mathrm{M}$ phosphate buffer $(\mathrm{pH} 7.0,1.40 \mathrm{~mL})$, and water $(0.70 \mathrm{~mL})$. The negative control was prepared using $\mathrm{MeOH}(0.30 \mathrm{~mL})$ instead of the sample. Peroxidation was initiated by the addition of $46.35 \mathrm{mM}$ AAPH solution in phosphate buffer $(0.20 \mathrm{~mL})$. The vial was incubated at $50.0 \pm 0.1{ }^{\circ} \mathrm{C}$ in the dark, sampling being carried out every hour for up to at least $5 \mathrm{~h}$ until the absorbance of the control reach the maximum value. The degree of oxidation was measured according to the ferric thiocyanate (FTC) method $[28,29]$. The reaction mixture $(0.10 \mathrm{~mL})$ was diluted with $75 \%(\mathrm{v} / \mathrm{v}) \mathrm{MeOH}(9.70 \mathrm{~mL})$ and mixed with $20 \mathrm{mM} \mathrm{FeCl} 2$ solution in $3.5 \%(\mathrm{w} / \mathrm{w}) \mathrm{HCl}(0.10 \mathrm{~mL})$ and $10 \%(\mathrm{w} / \mathrm{w})$ aqueous $\mathrm{NH}_{4} \mathrm{SCN}$ solution $(0.10 \mathrm{~mL})$. After precisely $3 \mathrm{~min}$ the absorbance was measured at $500 \mathrm{~nm}$ versus $75 \% \mathrm{MeOH}$. Possible interference of phenolic extracts with the FTC assay was investigated by adding an extract sample to the fully oxidised negative control and no interference was observed. The inhibition ratio (I\%) of the peroxidation process was calculated as follows: $I \%=100 \times\left(1-\Delta A_{\text {sample }} / \Delta A_{\text {control }}\right)$, where $\Delta A$ is the difference between the absorbance measured at the end and the start of the test.

\subsection{Determination of total phenolic content}

The total phenolic content in TE was determined according to Folin-Ciocalteu (FC) method [3]. Results were expressed as gallic acid (GAE) equivalents per dry weight of the plant material.

\subsection{Determination of total proanthocyanidin content}

The total proanthocyanidin content in TE was quantified by the modified acid/butanol assay [30]. An aliquot of TE $(0.5 \mathrm{~mL})$ was placed in a screw-cap vial and mixed with $n$-BuOH-35\% $\mathrm{HCl}(95: 5$, $\mathrm{v} / \mathrm{v}, 3 \mathrm{~mL})$ and $2 \%(\mathrm{w} / \mathrm{v}) \mathrm{NH}_{4} \mathrm{Fe}\left(\mathrm{SO}_{4}\right)_{2} \times 12 \mathrm{H}_{2} \mathrm{O}$ in $2 \mathrm{M} \mathrm{HCl}(0.1 \mathrm{~mL})$. After $45 \mathrm{~min}$ of incubation at $95.0 \pm 0.2{ }^{\circ} \mathrm{C}$ the vial was cooled to $25^{\circ} \mathrm{C}$, and the absorbance was read at $550 \mathrm{~nm}$ versus the unheated sample used as the blank. The results were expressed as cyanidin chloride (CyE) equivalents per dry weight of plant material.

\subsection{Total flavonoid content}

The content of flavonoids in TE was determined by RP-HPLC as the total content of flavonoid aglycones after acid hydrolysis, according to the method optimized and validated previously [31]. 


\subsection{The content of chlorogenic acid isomers}

The content of main caffeoylquinic acids in TE was estimated by RP-HPLC. The samples of TE were filtered through a syringe filter, and the filtrate was injected $(20 \mu \mathrm{L})$ into the HPLC system. The elution system consisted of solvent A ( $0.5 \%$ water solution of ortophosphoric acid, w/v) and solvent B $(\mathrm{MeCN})$ with the elution profile as follows: 0-1 min, 5\% B (v/v); 1-4 min, 5-15\% B; 4-10 min, 15\% B; 10-11 min, $15-50 \% \mathrm{~B}$; 11-15 min, 50\% B; 15-16 min, 50-5\% B; 16-22 min, 5\% B (equilibration). All gradients were linear. The flow rate was $1.2 \mathrm{~mL} / \mathrm{min}$, the column was maintained at $40{ }^{\circ} \mathrm{C}$, and the detection wavelength was set at $350 \mathrm{~nm}$. Two main chlorogenic acid isomers in TE were identified by comparison with the standards of 5-O-caffeoylquinic acid (chlorogenic acid, ChA, commercial standard) and 3-O-caffeoylquinic acid (neochlorogenic acid, NChA, qualitative standard prepared by isomerisation of ChA using the method of Nagels et al. [32]). The contents of the two isomers were expressed per dry weight of the plant material and were calculated from the calibration curve of ChA.

\subsection{Statistical analysis}

The statistics (calculation of standard deviation, analysis of variance, partitional and cluster analysis) were performed using the software StatisticaPl for Windows (StatSoft Inc., Poland).

\section{Conclusions}

The present study demonstrated that the studied plant materials possess significant and dosedependent in vitro radical-scavenging activity towards the DPPH radical and a strong ability to inhibit the AAPH-induced oxidation of linoleic acid, both of which correlate with their polyphenolic composition. Given the remarkably high phenolic content found in some tested materials (samples grouped in the cluster CL1), this study supports the idea that Sorbus products may be good sources of powerful natural antioxidants for use in food, medicine, cosmetics and other fields that require antioxidants. However, further research is needed to investigate the structure and antioxidant activity of the individual phenolic compounds constituting the analysed extracts. Further studies would also be desirable to clarify the possible toxicity and other biological properties of the species presented here; moreover, the effects of the use of these natural antioxidants on food, cosmetic or drug sensory properties (such as odour and taste) should be addressed in future research.

\section{Acknowledgements}

This work was financially supported by the Polish Ministry of Science and Higher Education (grant project: N N405 398037).

\section{References and Notes}

1. McAllister, H. The Genus Sorbus: Mountain Ash and Other Rowans; Royal Botanic Gardens, Kew: Surrey, UK, 2005.

2. Hukkanen, A.T.; Pölönen, S.S.; Kärenlampi, S.O.; Kokko, H.I. Antioxidant capacity and phenolic content of sweet rowanberries. J. Agr. Food Chem. 2006, 54, 112-119. 
3. Olszewska, M.A.; Michel, P. Antioxidant activity of inflorescences, leaves and fruits of three Sorbus species in relation to their polyphenolic composition. Nat. Prod. Res. 2009, 23, 1507-1521.

4. McCune, L.M.; Johns, T. Antioxidant activity in medicinal plants associated with the symptoms of diabetes mellitus used by the Indigenous Peoples of the North American boreal forest. $J$. Ethnopharmacol. 2002, 82, 197-205.

5. Bae, J.T.; Sim, G.S.; Kim, J.H.; Pyo, H.B.; Yun, J.W.; Lee, B.C. Antioxidative activity of the hydrolytic enzyme treated Sorbus commixta Hedl. and its inhibitory effect on matrix metalloproteinase-1 in UV irradiated human dermal fibroblasts. Arch. Pharm. Res. 2007, 30, 1116-1123.

6. Sohn, E.J.; Kang, D.G.; Mun, Y.J.; Woo, W.H.; Lee, H.S. Anti-atherogenic effects of the methanol extract of Sorbus cortex in atherogenic-diet rats. Biol. Pharm. Bull. 2005, 28, 1444-1449.

7. Kang, D.G.; Sohn, E.J.; Lee, A.S.; Kim, J.S.; Lee, D.H.; Lee, H.S. Methanol extract of Sorbus commixta cortex prevents vascular inflammation in rats with a high fructose-induced metabolic syndrome. Am. J. Chin. Med. 2007, 35, 265-277.

8. Kang, D.G.; Lee, J.K.; Choi, D.H.; Sohn, E.J.; Moon, M.K.; Lee, H.S. Vascular relaxation by the methanol extract of Sorbus cortex via NO-cGMP pathway. Biol. Pharm. Bull. 2005, 28, 860-864.

9. Termentzi, A.; Kefalas, P.; Kokkalou, E. Antioxidant activities of various extracts and fractions of Sorbus domestica fruit at different maturity stages. Food Chem. 2006, 98, 599-608.

10. Olszewska, M.A.; Michel, P. Activity-guided isolation and identification of free radicalscavenging components from various leaf extracts of Sorbus aria (Ehrh.) Pers. Nat. Prod. Res. 2011, in press.

11. Ndhlala, A.R.; Moyo, M.; Van Staden, J. Natural antioxidants: fascinating or mythical biomolecules? Molecules 2010, 15, 6905-6930.

12. Rice-Evans, C.A.; Miller, N.J.; Paganga, G. Structure-antioxidant activity relationship of flavonoids and phenolic acids. Free Radic. Biol. Med. 1996, 20, 933-956.

13. Cai, Y.; Luo, Q.; Sun, M.; Corke, H. Antioxidant activity and phenolic compounds of 112 traditional Chinese medicinal plants associated with anticancer. Life Sci. 2004, 74, 2157-2184.

14. Surveswaran, S.; Cai, Y.; Corke, H.; Sun, M. Systematic evaluation of natural phenolic antioxidants from 133 Indian medicinal plants. Food Chem. 2007, 102, 938-953.

15. Prior, R.L.; Wu, X.; Schaich, K. Standardized methods for the determination of antioxidant capacity and phenolics in foods and dietary supplements. J. Agr. Food Chem. 2005, 53, 4290-4302.

16. Sultana, B.; Anwar, F.; Przybylski, R. Antioxidant activity of phenolic components present in barks of Azadirachta indica, Terminalia arjuna, Acacia nilotica, and Eugenia jambolana Lam. Trees. Food Chem. 2007, 104, 1106-1114.

17. Yokozawa, T.; Chen, C.P.; Dong, E.; Tanaka, T.; Nonaka, G.I.; Nishioka, I. Study on the inhibitory effect of tannins and flavonoids against the 1,1-diphenyl-2-picrylhydrazyl radical. Biochem. Pharmacol. 1998, 56, 231-222.

18. Zimmerman, H.J. Hepatotoxicity: the Adverse Effects of Drugs and Other Chemicals on the Liver; Lippincott, Williams \& Wilkins: Philadelphia, PA, USA, 1999; pp. 274-275. 
19. Aron, P.M.; Kennedy, J.A. Flavan-3-ols: Nature, occurrence and biological activity. Mol. Nutr. Food Res. 2008, 52, 79-104.

20. Galati, G.; O’Brien, P.J. Potential toxicity of flavonoids and other dietary phenolics: significance for their chemopreventive and anticancer properties. Free Radic. Biol. Med. 2004, 37, 287-303.

21. Watanabe, T.; Arai, Y.; Mitsui, Y.; Kusaura, T.; Okawa, W.; Kajihara, Y.; Saito, I. The blood pressure-lowering effect and safety of chlorogenic acid from green coffee bean extract in essential hypertension. Clin. Exp. Hypertens. 2006, 28, 439-449.

22. Burda, S.; Oleszek, W. Antioxidant and antiradical activities of flavonoids. J. Agr. Food Chem. 2001, 49, 2774-2779.

23. Meyer, A.S.; Donovan, J.L.; Pearson, D.A.; Waterhouse, A.L.; Frankel, E.N. Fruit hydroxycinnamic acids inhibit human low-density lipoprotein oxidation in vitro. J. Agr. Food Chem. 1998, 46, 1783-1787.

24. Borneo, R.; Leon, A.E.; Aguirre, A.; Ribotta, P.; Cantero, J.J. Antioxidant capacity of medicinal plants from the Province of Cordoba (Argentina) and their in vitro testing in a model food system. Food Chem. 2009, 112, 664-670.

25. Scherer, R.; Godoy, H.T. Antioxidant activity index (AAI) by the 2,2-diphenyl-1-picrylhydrazyl method. Food Chem. 2009, 112, 654-658.

26. Brand-Williams, W.; Cuvelier, M.E.; Berset, C. Use of a free radical method to evaluate antioxidant activity. Lebensm. Wiss. Technol. 1995, 28, 25-30.

27. Azuma, K.; Nakayama, M.; Koshioka, M.; Ippoushi, K.; Yamaguchi, Y.; Kohata, K.; Yamauchi, Y.; Ito, H.; Higashio, H. Phenolic antioxidants from the leaves of Corchorus olitorius L. J. Agr. Food Chem. 1999, 47, 3963-3966.

28. Haraguchi, H.; Ishikawa, H.; Sanchez, Y.; Ogura, T.; Kubo, Y.; Kubo, I. Antioxidative constituents in Heterotheca inoloides. Bioorg. Med. Chem. 1997, 5, 865-871.

29. Chen, H.-M.; Muramoto, K.; Yamauchi, F.; Nokihara, K. Antioxidant activity of designed peptides based on the antioxidative peptide isolated from digests of a soybean protein. J. Agr. Food Chem. 1996, 44, 2619-2623.

30. Porter, L.J.; Hrstich, L.N.; Chana, B.G. The conversion of procyanidins and prodelphinidins to cyanidin and delphinidin. Phytochemistry 1986, 25, 223-230.

31. Olszewska, M. Separation of quercetin, sexangularetin, kaempferol and isorhamnetin for simultaneous HPLC determination of flavonoid aglycones in inflorescences, leaves and fruits of three Sorbus species. J. Pharm. Biomed. Anal. 2008, 48, 629-635.

32. Nagels, L.; van Dongen, W.; de Brucker, J.; de Pooter, H. High-performance liquid chromatographic separation of naturally occuring esters of phenolic acids. J. Chromatogr. 1980, 187, 181-187.

Sample Availability: Plant samples are available from the authors.

(C) 2010 by the authors; licensee MDPI, Basel, Switzerland. This article is an open access article distributed under the terms and conditions of the Creative Commons Attribution license (http://creativecommons.org/licenses/by/3.0/). 